\title{
Pembelajaran Penulisan Kalimat Majemuk dengan Self-learning CD
}

\author{
Yuliana Ambarsari \\ Yuliana.ambarsari@unindra.ac.id \\ Maguna Eliastuti \\ Maguna.eliastuti@gmail.com \\ Fakultas Pendidikan Bahasa dan Seni, Universitas Indraprasta PGRI \\ Jakarta
}

\begin{abstract}
ABSTRAK
Penelitian ini adalah sebagai pengaplikasian sebuah penelitian pengembangan model tentang prototipe media web-based yang kemudian diimplementasikan ke dalam bentuk CD untuk pembelajaran sendiri. Target dari penelitian lanjutan ini adalah untuk membantu peserta didik kelas 11 agar mereka dapat mengembangkan pengetahuan mereka tentang pembentukan kalimat majemuk (bertingkat dan setara) secara mandiri. Dengan CD pembelajaran mandiri ini, diharapkan kemampuan mereka dalam menulis karangan narasi menjadi lebih baik karena mereka mampu menulis kalimat majemuk setara/bertingkat dalam esai narasi yang mereka tulis.

Penelitian kuantitatif ini dilakukan dengan kuasi eksperimen dimana 30 peserta didik dari dua kelas 11 diambil secara acak sebagai sampel. Pre-tes dilakukan dengan meminta peserta didik menulis karangan narasi dengan tema "Best things in last vacation", dan pos-tes dilakukan dengan meminta mereka menulis karanga narasi bertema "Bad things in Last vacation." Setelah pre-tes, peserta didik diberikan CD pelatihan pembentukan kalimat bahasa Inggris selama satu minggu. Post-test dilakukan setelah mereka melakukan pembelajaran mandiri dengan menggunakan $\mathrm{CD}$. Hasil kemudian dinilai dengan menggunakan rubrik penilaian holistik (Brown , 2004, h.242). Hasil dari penghitungan SPSS 22.0 menyatakan bahwa terdapat hasil yang signifikan dari hasil pembelajaran mandiri dengan menggunakan CD pembelajaran Pembentukan Kalimat Majemuk.
\end{abstract}

Kata kunci: CD Pembentukan Kalimat Majemuk, pembelajaran mandiri, karangan narasi.

\begin{abstract}
This research is to apply a previous design-based research done for a web-based media ptototype which, then, is transformed into a self-learning $C D$. Its target is to help 11th high-school graders for compound/complex sentence building drill. By this self-learning $C D$, it is expected that the students can write better narration, as they are able to produce out compound and complex sentence.

This quantitative research is done under quasi-experimental method where thirty students are taken from two different classes randomly. Pretest is done by narrative writing done by the students themed "Best things in last vacation", and post test is done by narrative writing done by the students themed "Bad things in
\end{abstract}


Last vacation." After pre test, students are encouraged to do self-learning compound complex drill by the CD for a week. Post test is done exactly after their self-learning done completely. Score of writing output is taken under holistic writing scoring method (Brown, 2004, p .242). The result of pretest and post test that is analyzed by SPSS 22.0 results for a significant achievement for its appication.

Key words: Compound Complex CD, self-learning, narrative writing output.

\section{PENDAHULUAN}

Belajar bahasa Inggris untuk peserta didik umumnya dan untuk peserta didik menginjak usia remaja/murid SMA khususnya, terkadang menjadi hal yang sangat tidak mudah. Disamping metode pembelajaran yang terkadang tidak berkembang di dalam kelas dan jarangnya peserta didik belajar dengan menggunakan media seperti komputer, TV atau realia lainnya, penyajian bahasa Inggris yang kebanyakan dalam bentuk kalimat, paragraf sampai cerita panjang membuat mind-set mereka tentang bahasa Inggris menjadi sebuah alur proses pembelajaran yang panjang dan membosankan dengan hasil yang belum tentu menjanjikan.

Target ujian sekolah SMA adalah mengerti cerita dan bisa menjawab soalsoal terkait. Banyak peserta didik yang merasa kesulitan untuk mengerti kalimatkalimat panjang didalamnya. Guru sudah berusaha sedemikian rupa agar peserta didik mereka bisa mengerti beberapa jenis kalimat bertingkat yang terdapat pada cerita tersebut. Salah satu penggalan paparan panjang berikut ini adalah contoh dimana 80 persennya merupakan kalimat majemuk (bertingkat).

Berdasarkan riset pendahuluan, dimana 5 pertanyaan ditanyakan kepada 10 guru di Depok tentang proses belajar pembelajaran kalimat majemuk di SMA, delapan guru diantaranya berpendapat bahwa mereka membutuhkan pengulangan beberapa kali untuk mengajarkan kalimat majemuk terhadap peserta didik. Terkadang dalam proses latihan, peserta didik bisa melakukan soal-soal dengan cukup baik karena biasanya dilakukan berdua atau dalam grup. Tapi dalam pengujiannya, tetap saja ranah-ranah bahasa (tense, conjunction, subject, verb) dalam pembentukan kalimat majemuk masih belum mendapat hasil yang diekspektasikan.

Kebanyakan guru berpendapat bahwa mereka membutuhkan suatu media pembelajaran yang menarik, sehingga bisa membuat peserta didik mereka termotivasi. Selama ini mereka hanya menitik-beratkan pada latihan-latihan menulis dan berbicara. Sesuatu hal yang baru seperti film atau aplikasi yang menitikberatkan pada pembelajaran kalimat majemuk sangat diperlukan saat ini, entah itu untuk di sekolah, atau untuk mereka belajar sendiri di rumah. Oleh karena itu sebuah aplikasi yang berisi game dan latihan-latihan menulis dengan cara yang menarik dengan sistem belajar sendiri (self-learning) dikembangkan oleh peneliti. Suatu metode pembelajaran yang menitikberatkan pada sistem belajar sendiri yaitu silent way akan diaplikasikan kedalam proses desainnya. 
Mengapa silent way? Karena silent way merupakan suatu proses pembelajaran mandiri dan kreatif dimana guru hanya memberi contoh, biasanya dengan menggunakan batang atau stick, dan memotivasi peserta didik untuk bisa membuat kalimat setelahnya. Learning is facilitated if the learners discovers or creates rather than remembers and repeats what to be learned, by accompanying (mediating) physical objects and by problem solving involving the material to be learned (Richards, 1999, h. 99). Sebuah pembelajaran bahasa akan lebih berkesan ketika peserta didik mempelajari sesuatu yang baru atau menemukan sesuatu yang baru dalam proses pembelajaran. Menghapal dan mengulang terkadang terlihat bermanfaat dalam mempelajari sebuah bahasa dan terkesan bekerja dalam diri peserta didik, tetapi alangkah lebih baik jika peserta didik diminta untuk lebih kreatif baik dalam penerimaan bahasa maupun dalam proses output bahasa.

Penelitian ini merupakan penelitin lanjutan dari penelitian pengembangan model tentang prototipe media web-based. Berikut adalah review dari penelitian sebelumnya tentang pengembangan prototipe media web-base learning yang kemudian diimplementasikan ke dalam bentuk $\mathrm{CD}$. Pembentukan rangka dan dasar konsep CD dilakukan dengan pengkodean terbuka dan pengkodean axial. Pengkodean terbuka dilakukan terhadap tiga hal yaitu target pengajaran menulis bahasa untuk anak sekolah menengah atas kelas 10 dan kelas 11 yang tertera pada buku bahasa Inggris terbitan Kemendikbud, metode pembelajaran silent way dan teori pendukung lainnya. Lalu dilanjutkan dengan dilakukannya pengkodean axial dimana hasil akhir sebagai dasar konseptualisasi media adalah sebagai berikut:

1. Peserta didik membutuhkan kosakata yang lebih mudah dipahami untuk pembentukan kalimat. Target dari media nantinya adalah tidak hanya untuk pembentukan kalimat tetapi juga pengaplikasian kosakata. Media ini nantinya untuk peserta didik kelas 11. Oleh karena itu, functional vocabulary akan diaplikasikan di dalamnya.

2. Latihan untuk membentuk kalimat artinya adalah latihan tentang tata bahasa juga. Latihan tata bahasa akan dilakukan secara induktif.

3. Untuk mengimplikasikan silent way ke dalam media nantinya, pelatihan kosakata akan dilakukan dalam ice breaking yang akan diaplikasikan pada jeda latihan.

4. Dalam kalimat majemuk setara dan bertingkat, terdapat beberapa parts of speech (kata kerja, kata benda, kata sifat, kata keterangan) yang akan ditekankan pada beberapa ice breaking. subjek dan kata kerja adalah penting dalam pembentukan kalimat, maka untuk subjek dan kata kerja batang yang digunakan lebih panjang. Kapitalisasi dan tanda baca juga akan dimasukkan sebagai ice breaking.

5. Dengan berdasar pada metode silent way dimana pelatihan dilakukan dengan menggunakan batang berwarna, maka warna yang akan dipakai untuk batang adalah: merah, hijau, biru, orange, kuning, hitam, putih dan merah muda, dimana warna-warna tersebut adalah kuning untuk subjek, merah untuk kata kerja, hijau untuk kata sifat, putih untuk tanda baca, orange untuk kata keterangan (compliment), coklat untuk kata keterangan (adverb), dan hitam untuk kata penghubung. 
6. terdapat lima sampai dua puluh target kalimat untuk masing-masing set. Setiap kalimat berkembang dari yang termudah ke yang agak sulit.

Setelah disimpulkan dasar model media, maka rangka media tentang model pelatihan dalam bentuk soal dan permainan interaktif dibuat sebagai berikut:

\begin{tabular}{|c|c|}
\hline Model soal & Keterangan \\
\hline $\begin{array}{l}\text { Filling } \\
\text { blank/mengisi } \\
\text { bagian kosong }\end{array}$ & $\begin{array}{l}\text { Terdapat beberapa kalimat dalam batangan-batangan } \\
\text { dengan beberapa batang tanpa tulisan. Tugas user adalah } \\
\text { memindahkan beberapa pilihan yang tersedia ke dalam } \\
\text { kotak. }\end{array}$ \\
\hline $\begin{array}{l}\text { Jumble } \\
\text { sentence/menyusu } \\
\text { n kalimat }\end{array}$ & $\begin{array}{l}\text { Beberapa kata dalam batang dengan kata-kata yang terletak } \\
\text { tidak beraturan tersedia. Target hasil: pengguna harus bisa } \\
\text { memindahkan kata-kata dalam batang ke dalam urutan } \\
\text { kotak yang tersedia. }\end{array}$ \\
\hline $\begin{array}{l}\text { Picking in words } \\
\text { for a correct } \\
\text { sentence/memasu } \\
\text { kkan kata ke } \\
\text { dalam kalimat }\end{array}$ & $\begin{array}{l}\text { Terdapat banyak batangan dengan kata-kata yang berganti } \\
\text { setiap tiga menit. Tugas pengguna adalah menyusun } \\
\text { kalimat sederhana atau kalimat majemuk ke dalam kotak } \\
\text { yang tersedia. Petunjuk gambar diberikan untuk } \\
\text { memudahkan pengguna menyusun kalimat. }\end{array}$ \\
\hline $\begin{array}{l}\text { Picking out words } \\
\text { for a correct } \\
\text { sentence/membua } \\
\text { ng kata yang tidak } \\
\text { sesuai }\end{array}$ & $\begin{array}{l}\text { Terdapat banyak batangan dengan kata-kata. Tugas } \\
\text { pengguna adalah membuang kata-kata yang tidak berguna } \\
\text { untuk dibuat menjadi satu kalimat majemuk yang tepat. } \\
\text { Petunjuk gambar diberikan untuk memudahkan pengguna } \\
\text { menyusun kalimat. }\end{array}$ \\
\hline $\begin{array}{l}\text { Multiple } \\
\text { choices/pilihan } \\
\text { ganda }\end{array}$ & $\begin{array}{l}\text { Terdapat tampilan satu-persatu kalimat dari keseluruhan } 10 \\
\text { kalimat. Lalu terdapat beberapa pilihan jawaban untuk } \\
\text { melengkapi kalimat tersebut. Tiap pilihan hanya muncul } \\
\text { selama } 2 \text { detik dan hilang lagi. Berganti sebanyak } 5 \text { kali, } \\
\text { yaitu sebanyak jumlah pilihan jawabannya. Ketika } \\
\text { pengguna berhasil menjawab maka terdapat tanda checklist } \\
\text { dan terdengar suara "correct", "awesome", "wonderful". }\end{array}$ \\
\hline $\begin{array}{l}\text { Jumbled } \\
\text { paragraph/menyu } \\
\text { sun paragraf }\end{array}$ & $\begin{array}{l}\text { Terdapat beberapa kata-kata atau frase yang tampil dalam } \\
\text { barisan truk dengan warna yang berbeda-beda. Barisan truk } \\
\text { tersebut membentuk jumbled sentences. Tugas pengguna } \\
\text { adalah menyusun sususan truk tersebut untuk dijadikan } \\
\text { kalimat benar dan utuh. Katagori warna untuk truk adalah: } \\
\text { - Subjek berwarna kuning } \\
\text { - Kata kerja berwarna merah } \\
\text { - kata benda berwarna biru } \\
\text { - Present participle berwarna biru tua } \\
\text { - Past participle berwarna tosca } \\
\text { - Kata sifat berwarna hijau }\end{array}$ \\
\hline
\end{tabular}




\begin{tabular}{|c|c|}
\hline & $\begin{array}{l}\text { - Tanda baca berwarna putih } \\
\text { - Kata keterangan (compliment) berwarna orange } \\
\text { - Kata keterangan (adverb) berwarna coklat } \\
\text { - Kata hubung berwarna hitam }\end{array}$ \\
\hline $\begin{array}{l}\text { Inserting present } \\
\text { participle/past } \\
\text { participle/memas } \\
\text { ukkan present } \\
\text { participle/past } \\
\text { participle ke } \\
\text { dalam kalimat }\end{array}$ & $\begin{array}{l}\text { Terdapat display kalimat sederhana yang tidak lengkap. } \\
\text { Kalimat tampil dalam batang-batang berwarna yang } \\
\text { mengapung di atas air. Batang-batang mengikuti jalannya } \\
\text { arus dari kanan ke kiri. Terdapat beberapa pilihan jawaban } \\
\text { mungkin di pinggir sungai dalam batang-batang berwarna. } \\
\text { Warna pilihan jawaban yang benar akan berbeda dengan } \\
\text { warna batang-batang tanpa tulisan yang mengapung di atas } \\
\text { sungai. Tugas pengguna adalah untuk dapat memilih } \\
\text { jawaban yang benar dalam batang-batang di pinggir sungai } \\
\text { dan memasukkan kata atau frasa yang tepat ke dalam kotak } \\
\text { yang kosong. Jika batang yang berjalan sudah menyentuh } \\
\text { ujung layar kiri dan pengguna belum memindahkan } \\
\text { jawaban benar ke dalam batang yang kosong, maka } \\
\text { jawaban dianggap salah. Jika jawaban benar maka akan } \\
\text { berbunyi "correct", "awesome", "wonderful". Jika jawaban } \\
\text { salah maka akan terdengar "sorry, try again later", "It is } \\
\text { oke, try again after this". }\end{array}$ \\
\hline $\begin{array}{l}\text { True or false } \\
\text { /betul atau salah }\end{array}$ & $\begin{array}{l}\text { Soal ini agak terlihat klasik karena hanya akan terlihat } \\
\text { seperti soal-soal salah benar tradisional. Hanya saja soal- } \\
\text { soal akan ada dalam batang-batang dengan katagori: } \\
\text { - Subjek berwarna kuning } \\
\text { - Kata kerja berwarna merah } \\
\text { - kata benda berwarna biru } \\
\text { - Present participle berwarna biru tua } \\
\text { - Past participle berwarna tosca } \\
\text { - Kata sifat berwarna hijau } \\
\text { - Tanda baca berwarna putih } \\
\text { - Kata keterangan (compliment) berwarna orange } \\
\text { - Kata keterangan (adverb) berwarna coklat } \\
\text { Kata hubung berwarna hitam, dimana jika jawaban benar } \\
\text { maka akan ada gambar tepuk tangan dan kata-kata } \\
\text { "correct", "awesome", atau "wonderful". Jika jawaban } \\
\text { salah maka akan terihat gambar silang merah besar dan } \\
\text { terdengar suara "tet-tot". }\end{array}$ \\
\hline $\begin{array}{l}\text { multiple } \\
\text { choices/pilihan } \\
\text { ganda }\end{array}$ & $\begin{array}{l}\text { Soal ini agak terlihat klasik karena hanya akan terlihat } \\
\text { seperti soal-soal pilihan ganda tradisional. Hanya saja soal- } \\
\text { soal akan ada dalam batang-batang dengan warna sama } \\
\text { yaitu putih. Jawaban yang tersedia akan berupa kalimat } \\
\text { lengkap dalam batang-batang dengan katagori: }\end{array}$ \\
\hline
\end{tabular}




\begin{tabular}{|c|c|}
\hline & $\begin{array}{l}\text { - Subjek berwarna kuning } \\
\text { - } \text { Kata kerja berwarna merah } \\
\text { - } \text { kata benda berwarna biru } \\
\text { - } \text { Present participle berwarna biru tua } \\
\text { - Past participle berwarna tosca } \\
\text { - Kata sifat berwarna hijau } \\
\text { - } \text { Tanda baca berwarna putih } \\
\text { - Kata keterangan (compliment) berwarna orange } \\
\text { - Kata keterangan (adverb) berwarna coklat } \\
\text { - } \text { Kata hubung berwarna hitam }\end{array}$ \\
\hline $\begin{array}{l}\text { Completing } \\
\text { dialogue/melengk } \\
\text { api dialog }\end{array}$ & $\begin{array}{l}\text { Dalam katagori ini, terdapat beberapa model melengkapi } \\
\text { dialog, yaitu: } \\
\text { 1. terdapat dialog yang di beberapa bagiannya ditaruh } \\
\text { batang-batang kosong, dimana bagian-bagian batang- } \\
\text { batang tersebut adalah bagian-bagian yang hilang dan } \\
\text { harus dilengkapi pengguna. Batang-batang yang } \\
\text { kosong yang harus dilengkapi sesuai dengan katagori: } \\
\text { - Subjek berwarna kuning } \\
\text { - Kata kerja berwarna merah } \\
\text { - kata benda berwarna biru } \\
\text { - Present participle berwarna biru tua } \\
\text { - Past participle berwarna tosca } \\
\text { - Kata sifat berwarna hijau } \\
\text { - Tanda baca berwarna putih } \\
\text { - Kata keterangan (compliment) berwarna orange } \\
\text { - Kata keterangan }(a d v e r b) \text { berwarna coklat } \\
\text { - Kata hubung berwarna hitam }\end{array}$ \\
\hline $\begin{array}{l}\text { Completing } \\
\text { paragraph/melen } \\
\text { gkapi paragraf }\end{array}$ & $\begin{array}{l}\text { 1. Terdapat beberapa kalimat majemuk yang dipisah } \\
\text { bagian klausa pertama dengan klausa keduanya dimana } \\
\text { pengguna diharapkan bisa menggabungkan kalimat- } \\
\text { kalimat tersebut kemudian men-drag tiap-tiap } \\
\text { kalimatnya ke dalam kolom paragraf yang sudah } \\
\text { disediakan. } \\
\text { 2. Terdapat gambar tentang suatu rangkaian cerita. } \\
\text { Terdapat beberapa kalimat yang harus disusun untuk } \\
\text { bisa menceritakan cerita yang ditampilkan. Kalimat } \\
\text { yang di-drag ke dalam kotak yang tersedia untuk } \\
\text { meyusun paragraf , jika kalimat itu salah } \\
\text { pengaturannya, maka akna berubah merah. Jika kalimat } \\
\text { itu benar maka kalimat itu akan berubah warna menjadi } \\
\text { putih. Kotak yang tersedia untuk membuat paragraf } \\
\text { adalah kotak berwarna biru langit. }\end{array}$ \\
\hline
\end{tabular}


Berikut adalah konseptualisasi media yang kemudian diproses ke tampilan gambar dalam CD:

Display: ada gambar dengan beberapa batang yang divariasi bentuknya. Untuk masing-masing gambar ada 7 kotak. Gambarnya adalah 2 anak gadis (tinggi gemuk) dan laki-laki remaja (pendek kurus). Target kalimat adalah: The two girls are tall, but the boy is short.

Tabel 1. Contoh konsep CD

\begin{tabular}{|c|c|c|c|c|c|c|c|c|}
\hline \multirow{5}{*}{ Gambar } & batang & batang & batang & Batang & Batang & batang & batang & batang \\
kuning & merah & hijau & putih & hitam & kuning & merah & hijau \\
dengan & dengan & dengan & dengan & dengan & dengan & dengan & dengan \\
& tulisan & tulisan & tulisan & tanda & tulisan & tulisan & tulisan & tulisan \\
& the two \\
girls & are & tall & koma & but & the boy & is & short \\
& & & & & & & \\
\hline
\end{tabular}

Gambar 1. Tampilan pada CD

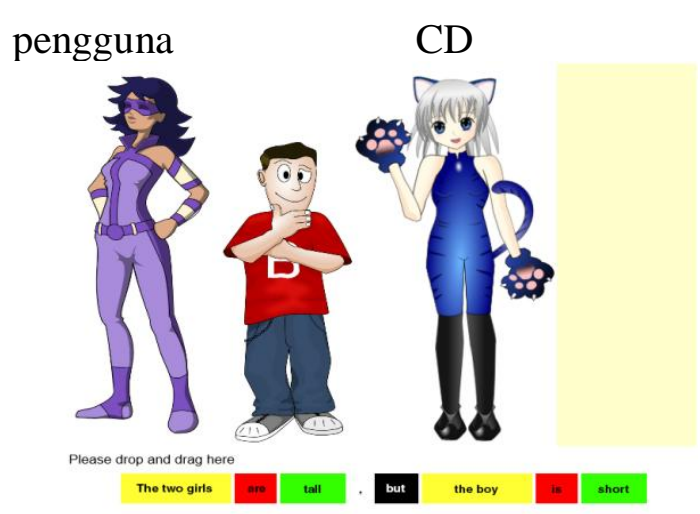

Gambar 2. Ekspektasi hasil kerja

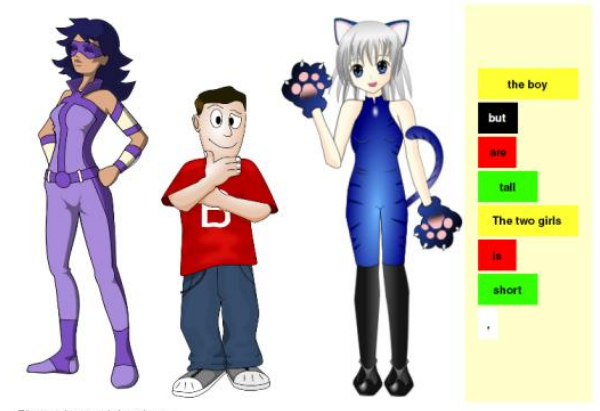

Berikut adalah konsep salah satu ice breaking yang ada dalam CD:

Judulnya adalah regular and irregular verbs dimana tujuannya adalah agar pengguna bisa berfikir cepat dan kreatif tentang kosakata. Terdapat set untuk tiga level yang dinamakan Beginner, Runner, Fast Runner. Prosedur main dalam icebreaking ini adalah memasukkan kata-kata ke dalam kotak katagori: regular verb, irregular verb, tidak boleh kurang dari waktu yang ditentukan dimana: 1 menit 
untuk Beginner, 2 menit untuk Runner, 3 menit untuk Beginner. Jika pengguna sudah selesai mengerjakan tiap soal, maka akan ada notifikasi seperti: "Congratulation. You are a good/awesome/excellent beginner/runner/fast runner."

Tampilan layar pada ice breaking ini adalah judul pada layar atas, kotak kata yang diacak untuk dikatagorikan ke regular dan irregular verbs pada layar tengah dan kotak katagori yang tersedia di kanan bawah dan kiri bawah layar. Pada kanan bawah layar adalah kotak irregular verb dan pada kiri bawah layar adalah regular verb.

\section{Audio}

Diberikan informasi tentang arti irregular dan regular verb: "Irregular verbs are those that change letter or that still be the same in three different forms: present, past and future. Go is an irregular verb as it changes to went for past form and to gone for participle form."

Diberikan information dari prosedur game dengan tampilan: "Match Each Word Catagory by Dragging Them in either Irregular Verbs or Regular Verbs."

Contoh diberikan dengan menampilkan 20 kata dengan sembilan kata yang pindah ke kotak irregular dan 10 kata pindah ke regular. Satu kata tetap ditempat. Perpindahan kata hanya terjadi kurang dari 1 menit. Dari 20 kata yang dipindahkan, terdapat 5 kata yang merupakan kata sifat dan kata benda.

Tampilan contoh:

Leave, become, grow, lead, keep, tell, hang on, fall, feel, wash, call, open, pull, drop off, listen to, ask, note, competence, marque, confidential.

Untuk level Beginner akan ada 25 kata yang tampil, yaitu:

Go, sit, speak, swim, run, say, have, drink, hit, sleep, spend, major, submit, talk, maintain, collect, want, step out, grab, cash, carrier, personal, outstanding, mannered.

Untuk level Runner akan ada 25 kata yang tampil, yaitu 25 kata untuk regular dan irregular verb. Kata-kata outlayers adalah adjective, noun, and adverbs.

Sell, know, think, teach, dig, sink, shrink, bring,

Visit, reject, hire, count, look, shower, explain, lecture, return, cheer.

Cash, worried, smell, fire, scared, noise, assignment, across, appologize, optimistic.

Untuk level Fast Runner akan ada 50 kata yang tampil, yaitu:

30 kata untuk regular dan irregular. Kata-kata outlayers adalah adjective, noun, adverbs, connectors.

Read, give, have, ride, find, win, hear, make, swear in, take, buy, have, do, fly, meet, draw, hide, know, catch, choose, see, mean, put, shake, dash, shop, fetch, die, live, seek for, interview, pray, mark, tidy up, organize, involve, develop, finalize, experience, chuckle, through, weather, finally, pessimistic, expensive, ago, travell, hapen, vendor, so forth.

Dari konsep tersebut, tampilannya untuk beginner adalah: 
Gambar 3. Contoh tampilan ice breaking

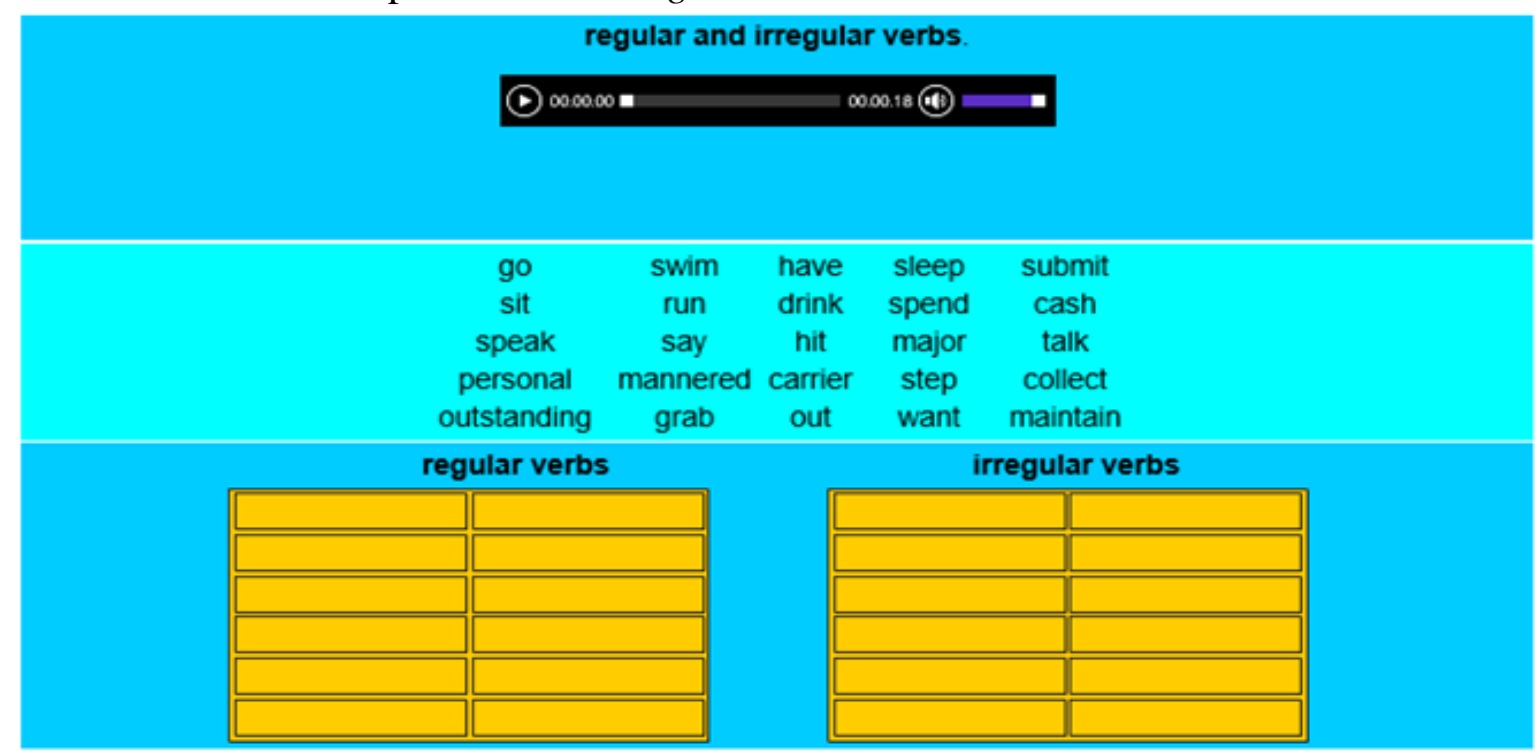

Terdapat kira-kira lebih dari 300 kalimat majemuk yang disajikan dalam CD nantinya yang bisa dijadikan latihan peserta didik untuk mengembangkan kemampuan menulis kalimat majemuk setara dan bertingkat.

\section{Penulisan Narasi dan Penilaian Menulis}

Pelatihan kemampuan menulis bahasa Inggris pada buku bahasa Inggris SMA (Kemendikbud: 2014) terutama dari segi pembangunan kalimat majemuk kurang terlihat. Yang tertera biasanya adalah pelatihan pemasukkan kata dalam kalimat atau paragraf. Sedangkan menurut Effendy dalam menulis esai, peserta didik harus mengetahui bagaimana menyusun kata-kata yang teratur dalam klausa juga kalimat agar pembaca dapat mengerti ide apa yang disampaikan oleh penulis (2017). Berdasarkan kenyataan yang ada, suatu model esai yang pastinya menarik perlu ditengarai untuk diimplikasikan kepada peserta didik agar kemampuan menulis bahasa Inggris yang terbatas dapat ditingkatkan dengan membawa kesukaan peserta didik pada apa yang ditulis.

Menulis narasi bisa membawa tema pada masa lampau baik yang menyenangkan maupun yang kurang menyenangkan. Menulis narasi merupakan menulis suatu kejadian runtut sesuai dengan urutan waktu atau kronologis kejadiannya. Tahapan menulis narasi adalah dengan merumuskan tema yang jelas, menentukan sasaran pembaca, menentukan ide atau pemikiran yang akan disampaikan, membuat daftar topik sesuai dengan tema, merancang peristiwa utama yang akan ditampilkan dalam bentuk skema akurat, membuat rancangan peristiwa-peristiwa kecil sebagai tambahan bumbu cerita, menyusun tokoh atau pemain, latar cerita, menulis cerita dan menyunting karangan.

Menulis narasi membawa sensasi sendiri untuk penulisnya. Menurut Sword sebuah sensasi dari narasi dalam artikel menciptakan ketertarikan sendiri pada siapa yang terlibat dengannya. A book or article that supplies no suspense, no narrative arc, and no sense of moving from $A$ to $B$ will not hold the reader's attention nearly as effectively as an article plotted (2012, h.87). Sebuah penelitian yang dilakukan oleh Larsen dan Freeman pada tahun 2006 (Byrnes \& Manchon et 
al, 2014, h.111) tentang kemampuan menulis dan berbicara imigran perempuan dalam konteks kelancaran bahasa, keakuratan bahasa dan kompleksitas bahasa, dimana untuk latihan menulis menggunakan narasi terbukti bahwa peserta menunjukkan kemajuan kemampuan menulis yang signifikan. Tidak hanya dalam bahasa asing, dalam bahasa tradisionalpun, yaitu bahasa jawa, narasi bisa membuat semua peserta didik nyaman ketika mereka harus menarasikan sebuah cerita (Sukamto \& Purwo, h.2016). Penelitian ini dilakukan pada peserta didik di Gunung kidul dengan membandingkan kemampuan deskriptif dan naratif dalam bercerita. Hasil penelitian ini menyimpulkan bahwa peserta didik berhasil meningkatkan kemampuan berceritanya dengan cepat dengan menggunakan model naratif daripada ketika mereka menggunakan model deskriptif. Oleh karena itulah, penulisan narasi dinilai sangat tepat untuk dipergunakan dalam penelitian ini.

Penilaian kemampuan menulis narasi adalah sama dengan penilaian penulisan jenis esai lain. Terdapat tiga metode dalam penilaian menulis yaitu holistic scoring, primary trait scoring, dan analytic scoring (Brown, 2004, h.242). Dari ketiganya, holistic scoring merupakan penilaian yang paling tepat dalam penelitian ini karena treatment dalam penelitian ini dilakukan dalam waktu yang tidak lama dan menggunakan fast evaluation atau menilai secara cepat. Penilaian ini agak berbeda dengan primary trait scoring dan analytic scoring. Yang dinilai pada penilaian holistik adalah kualitas dari tulisan, pengorganisasian kalimat juga tata bahasa. Dalam penilaian holistik yang menjadi acuan adalah bagaimana pembuat tes dan guru mengerti tujuan penerapan tes kemampuan menulis kepada peserta didik sehingga mereka tahu bagaimana cara menilainya. Sedikit umpan balik atau washback yang diberikan guru dalam tes ini. Meskipun terdapat beberapa kekurangan dalam metode penilaian ini, penilaian ini sangat aplikatif untuk berbagai jenis disiplin pendidikan.

Karena tujuan dari CD ini adalah sebagai pengaplikasian media belajar mandiri bagi peserta didik, tujuan dari penelitian ini adalah untuk mengetahui apakah ada peningkatan yang signifikan terhadap kemampuan menulis narasi bahasa Inggris oleh peserta didik setelah pengaplikasian CD ini.

\section{METODE PENELITIAN}

Seperti telah diutarakan sebelumnya bahwa penelitian ini merupakan penelitian lanjutan setelah penelitian pertama dengan pendekatan design based research. Berbeda dengan penelitian sebelumnya, penelitian ini menggunakan pendekatan kuantitatif dengan menggunakan metode kuasi eksperimen. Penelitian ini merupakan tahapan eksperimen dari penelitian sebelumnya, atau tahapan terakhir. Penelitian sebelumnya merupakan tahapan proses penelitian seperti yang tergambar dalam skema penelitian keseluruhan di bawah ini:

Gambar 4. Skema Penelitian Keseluruhan

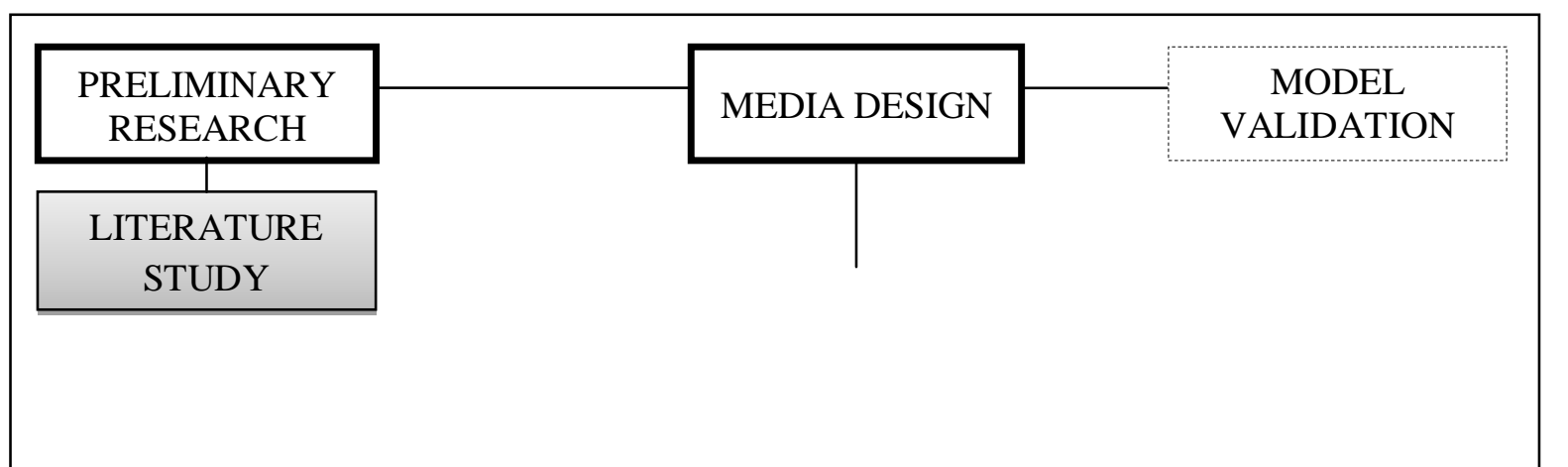




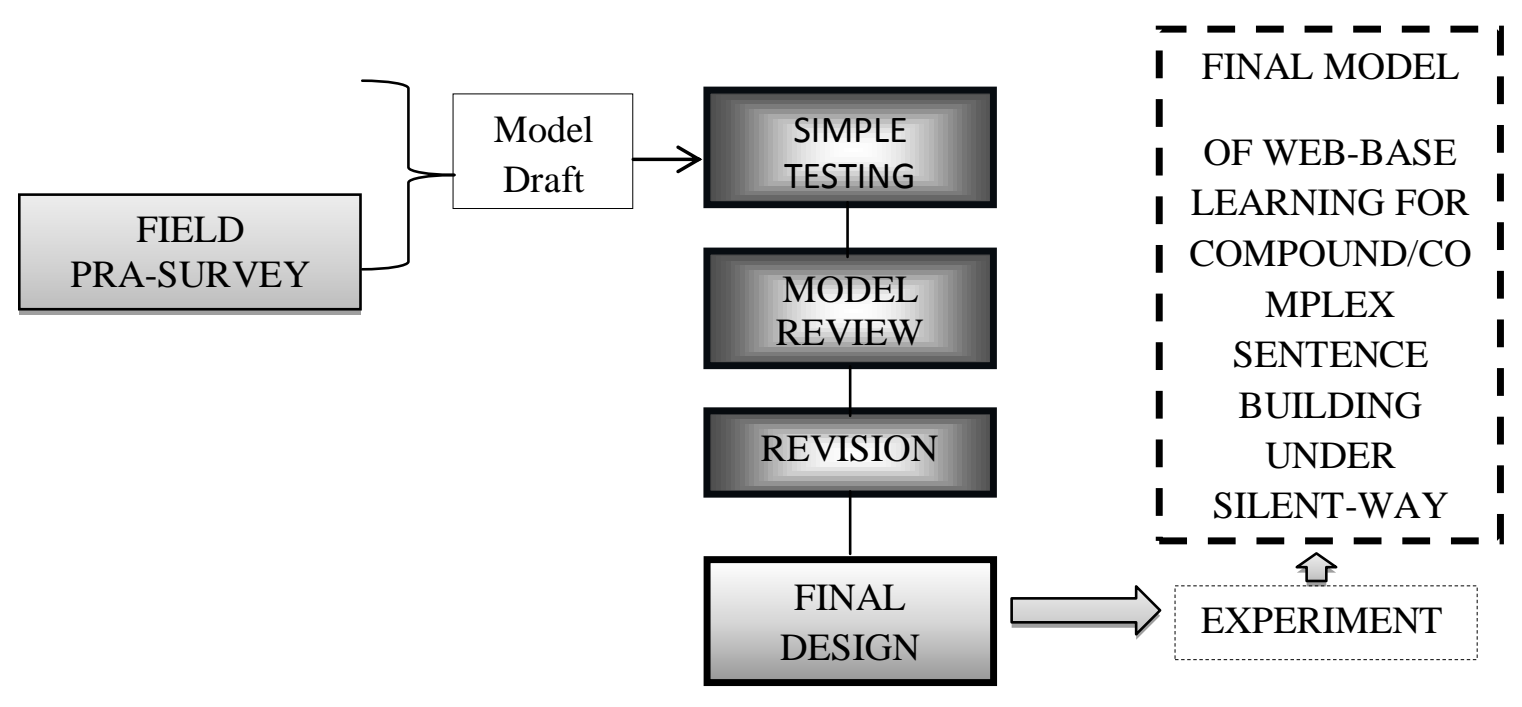

Sampel yang akan menjadi target dalam penelitian ini adalah peserta didik kelas 11 dan 12. Tetapi karena kelas 12 sudah dalam masa persiapan UN, maka sampel yang akan diambil hanya peserta didik kelas 11. Sampel diambil secara acak dari dua kelas di SMK Islamiyah Serua, Depok sebanyak 30 orang. Pre-tes dilakukan dengan memberikan tes menulis karangan narasi dengan judul "Best Things in My Last Vacation", dan post-tes dilakukan dengan memberikan tes menulis karangan narasi dengan judul "Bad Things in My Last Vacation." Kedua tes dinilai dengan menggunakan skor penilaian holistik dari Brown (2004,243235) dengan total skor 100.

\section{PEMBAHASAN}

Penghitungan nilai dilakukan dengan penghitungan SPSS 20.0. Angka yang diproses adalah nilai pre-tes dan post-tes peserta didik yaitu sebagai berikut:

Tabel 2. Nilai pre-tes dan post-tes

\begin{tabular}{|c|c|c|c|}
\hline No & Nama & $\begin{array}{c}\text { Pre- } \\
\text { tes }\end{array}$ & $\begin{array}{c}\text { Post- } \\
\text { tes }\end{array}$ \\
\hline 1 & RF & 83 & 87 \\
\hline 2 & ER & 75 & 77 \\
\hline 3 & FI & 76 & 77 \\
\hline 4 & RK & 60 & 75 \\
\hline 5 & DSP & 77 & 80 \\
\hline 6 & DH & 79 & 84 \\
\hline 7 & MM & 73 & 77 \\
\hline 8 & AR & 77 & 79 \\
\hline 9 & KN & 72 & 75 \\
\hline
\end{tabular}

\begin{tabular}{|c|c|c|c|}
\hline No & Nama & $\begin{array}{c}\text { Pre- } \\
\text { tes }\end{array}$ & $\begin{array}{c}\text { Post- } \\
\text { tes }\end{array}$ \\
\hline 16 & $\mathrm{NR}$ & 68 & 71 \\
\hline 17 & $\mathrm{MT}$ & 78 & 79 \\
\hline 18 & $\mathrm{Mr}$ & 73 & 75 \\
\hline 19 & $\mathrm{Ft}$ & 72 & 78 \\
\hline 20 & $\mathrm{Bt}$ & 73 & 78 \\
\hline 21 & $\mathrm{Y} 1$ & 70 & 71 \\
\hline 22 & $\mathrm{Am}$ & 72 & 77 \\
\hline 23 & $\mathrm{Nr}$ & 68 & 81 \\
\hline 24 & $\mathrm{Nr}$ & 60 & 67 \\
\hline
\end{tabular}




\begin{tabular}{|c|c|c|c|}
\hline 10 & ETH & 74 & 78 \\
\hline 11 & Sl & 83 & 85 \\
\hline 12 & RA & 74 & 76 \\
\hline 13 & Z & 73 & 80 \\
\hline 14 & RZ & 72 & 80 \\
\hline 15 & Dw & 70 & 72 \\
\hline
\end{tabular}

\begin{tabular}{|c|c|c|c|}
\hline 25 & Ad & 60 & 70 \\
\hline 26 & DH & 79 & 84 \\
\hline 27 & Uf & 76 & 78 \\
\hline 28 & SW & 70 & 73 \\
\hline 29 & Rt & 78 & 80 \\
\hline 30 & Ln & 74 & 76 \\
\hline
\end{tabular}

Penghitungan nilai dilakukan dengan membandingkan kemampuan pembangunan kalimat bahasa inggris peserta didik sekolah menengah atas kelas XI dengan menulis karangan narasi dengan pre-tes dan post-tes. Setelah pre-tes diberikan perlakuan (treatment) berupa menggunakan alat pembelajaran yaitu CD pembelajaran. Post-tes dilakukan setelahnya. Hasil analisis deskriptif dari nilai pre-tes dan post-tes adalah sebagai berikut:

Paired Samples Statistics

\begin{tabular}{|c|c|c|c|c|c|}
\hline & & Mean & $\mathrm{N}$ & Std. Deviation & $\begin{array}{l}\text { Std. Error } \\
\text { Mean }\end{array}$ \\
\hline \multirow[t]{2}{*}{ Pair 1} & Sesuda & 77,3333 & 30 & 4,54353 &, 82953 \\
\hline & Sebelum & 72,9667 & 30 & 5,77440 & 1,05426 \\
\hline
\end{tabular}

Berdasarkan ouput SPSS versi 22.0 menunjukkan bahwa rerata kemampuan pembangunan kalimat bahasa Inggris peserta didik sebelum menggunakan media $\mathrm{CD}$ sebesar 72,97, sedangkan setelah diberikan treatment rerata kemampuan peserta didik menjadi 77,33. Sehingga secara deskriptif terkatahui rerata kemampuan peserta didik mengalami peningkatan setelah diberikannya treatment berupa $\mathrm{CD}$ pembelajaran.

Paired Samples Correlations

\begin{tabular}{|ll|r|r|r|}
\hline & \multicolumn{1}{|c|}{$\mathrm{N}$} & Correlation & \multicolumn{1}{c|}{ Sig. } \\
\hline Pair 1 & Sesudah \& Sebelum & 30 &, 803 &, 000 \\
\hline
\end{tabular}

Output SPSS ini menunjukkan data yang digunakan untuk membuktikan bahwa penggunakan media pembelajaran $\mathrm{CD}$ memiliki pengaruh positif berasal dari 30 responden yang dijadikan subjek penelitian.

Paired Samples Test

\begin{tabular}{|l|l|l|l|l|}
\hline Paired Differences & $\mathrm{t}$ & $\mathrm{df}$ & Sig. (2- \\
\hline
\end{tabular}




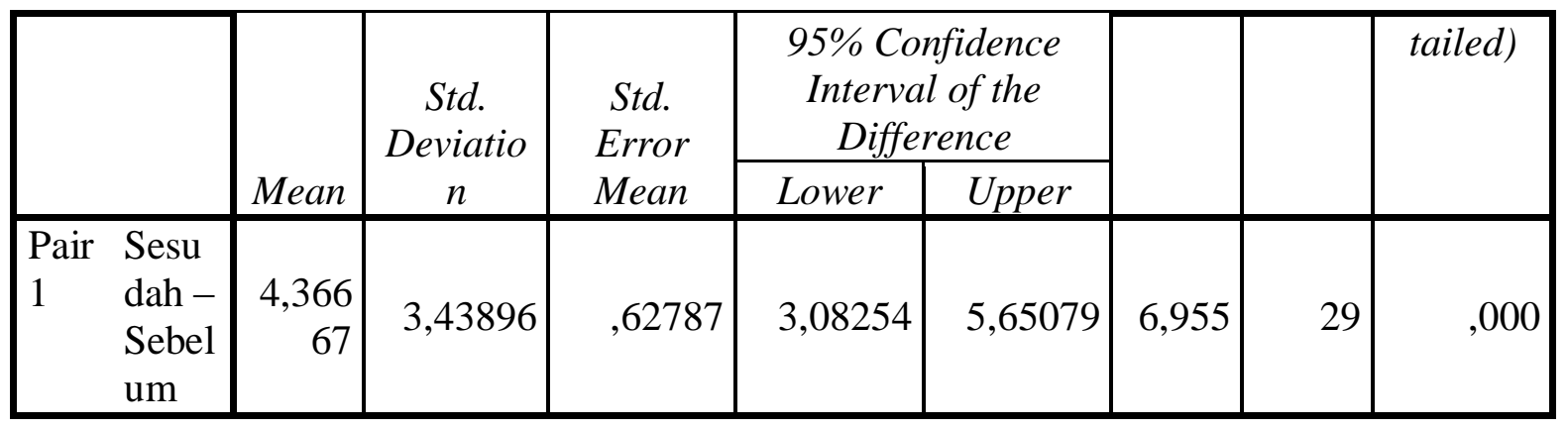

Output SPSS pada paired sample test menunjukkan adanya perbedaan rata-rata (mean) antara sebelum dan sesudah penggunaan media pembelajaran CD. Besarnya korelasi antara sebelum dan sesudah yaitu 0,803 dengan taraf signifikansi 0,000 .

Pengajuan hipotesis dalam penelitian ini adalah jika:

H0 : tidak terdapat peningkatan kemampuan pembangunan kalimat bahasa Inggris setelah digunakan media pembelajaran $\mathrm{CD}$, dan jika

$\mathrm{H} 1$ : terdapat peningkatan kemampuan pembangunan kalimat bahasa Inggris setelah digunakan media pembelajaran CD

Berdasarkan hasil analisis SPSS sig sebesar 0,000, ternyata $\alpha=0,05$ lebih besar dari nilai sig atau 0,05 >0,00, maka Ho ditolak dan H1 diterima. Artinya terdapat peningkatan kemampuan pembangunan kalimat bahasa Inggris setelah digunakan media pembelajaran CD. Pada tabel paired sample test menunjukkan nilai $t_{\text {hitung }}$ sebesar 6,955 dengan tingkat sig $=0,00$ dengan $\mathrm{df}=\mathrm{N}-1=29$ sehingga $\mathrm{t}_{\text {tabel }}=$ 2,045 pada taraf signifikan $\alpha=0,05$. Ternyata $t_{\text {hitung }}>t_{\text {tabel }}$ atau 6,955 $>2,045$, maka $\mathrm{H}_{0}$ ditolak dan $\mathrm{H}_{1}$ diterima, artinya terdapat peningkatan kemampuan pembangunan kalimat bahasa Inggris setelah digunakan media pembelajaran CD.

\section{SIMPULAN}

Silent way yang masing merupakan metode yang jarang dipergunakan dalam pelatihan kelas menulis bahasa Inggris terbukti dapat meningkatkan kemampuan menulis narasi peserta didik kelas XI secara menyeluruh. Hasil yang didapat adalah hasil keseluruhan yang menyatakan bahwa CD ini secara jelas bisa meningkatkan kemampuan menulis karangan narasi bahasa Inggris peserta didik. Para peserta didik dalam sampel juga menyatakan bahwa CD ini bisa membawa mereka berfikir kritis, kreatif dan fungsional. Tanpa sadar mereka telah mempelajari pembentukan kalimat majemuk setara dan bertingkat dengan baik. Kesulitan dari pembentukan kalimat majemuk setara dan bertingkat, menurut sebagian besar sampel, sebelum menggunakan CD terasa sangat melimitasi kemampuan mereka dalam menyampaikan ide dalam tulisan. Tetapi ketika mereka sudah melatih diri mereka sendiri dengan self-learning CD ini, kesulitan yang sebelumnya dirasa agak mengganggu, menjadi berkurang.

Meskipun penelitian secara detail dengan menggunakan metode kualitatif tentang seberapa besar kemajuan kemampuan menulis kalimat majemuk dalam 
karangan narasi pada masing-masing peserta didik tidak dilakukan dalam penelitian ini, sangat diharapkan hal ini bisa dilakukan dalam penelitian lanjutan. Apabila ada peneliti lain yang ingin mengujicobakan penggunaan media untuk meningkatkan kemampuan manulis kalimat majemuk setara atau bertingkat, metode studi kasus dalam pendekatan kualitatif akan lebih baik untuk dilakukan karena akan lebih jelas menggambarkan secara detail kemajuan hasil luaran bahasa dari peserta didik dalam grup atau dalam individu.

\section{DAFTAR PUSTAKA}

Brown, C. 2013. Vocabulary Games and Activities. Cambridge: Ucles..

Byrnes, H. and Manchon, R.M et al. (2014). Task-based Language Learninginsights from and for L2 Writing: Task Based Language Teaching. John Benjamin Publishing. Vol 7. Eds. Bygate, M., Noris, J.M., Van den Branden, K. Philadelphia: John Benjamin Publishing Company.

Effendy, A. (2017). Hakikat Keterampilan Menulis. Diunduh 13 Oktober 2017 dari https:/www.kompasiana.com/akipeffendy/hakikat-keterampilanmenulis_55eb183a33311b12dba83af.

Gattegno, Caleb. 1972. Teaching foreign languages in schools: the silent way, 2nd ed. (New York: educational Solution:inc).

Kementerian Pendidikan dan Kebudayaan Republik Indonesia. 2014. Bahasa Inggris SMA/MA/SMK/MAK Kelas $X$ Semester 1. Pusat Kurikulum dan Perbukuan, Balitbang, Kemdikbud.

Kementerian Pendidikan dan Kebudayaan Republik Indonesia. 2014. Bahasa Inggris SMA/MA/SMK/MAK Kelas X Semester 2. Pusat Kurikulum dan Perbukuan, Balitbang, Kemdikbud.

Kementerian Pendidikan dan Kebudayaan Republik Indonesia. 2014. Bahasa Inggris SMA/MA/SMK/MAK Kelas XI Semester 1. Pusat Kurikulum dan Perbukuan, Balitbang, Kemdikbud.

Kementerian Pendidikan dan Kebudayaan Republik Indonesia. 2014. Bahasa Inggris SMA/MA/SMK/MAK Kelas XI Semester 2. Pusat Kurikulum dan Perbukuan, Balitbang, Kemdikbud.

Patil. Y.R. 2014. The Silent way and Two Other mthods of Language Teaching. Online International interdisciplinary research journal $\{\mathrm{Bi}-\mathrm{Monthly}\}$, ISSN2249-9598, Volume-IV, Issue-V, Sept-Oct 2014. Retrieved from oiirj.org/oiirj/blog/2014/09/01/vol-iv-issue-v-sept-oct-2014.

Richards, J.C. and Rodgers, T.S. 1999. Approaches and Methods in Language Teaching. New York: Cambridge University Press.

Sukamto, K.E. \& Purwa, B.K. (2016). Oral Narrative and Descriptive Proficiency in Bilingual Children: A Case Study of Javanese-Indonesian Children. Jurnal Ilmiah Masyarakat Indonesia. ISSN 0215-4846. Vol.34 No. 1. Jakarta: MLI. 
Sword, Helan. (2012). Stylish Academic Writing. London: Harvard University Press.

Thornbury, S. (2007). How to Teach Grammar. England: Pearson 